Tribe, John and Liburd, Janne J. ORCID:

https://orcid.org/0000-0002-3884-6728 (2016) The tourism knowledge system. Annals of Tourism Research, 57. pp. 44-61.

Downloaded from: http://ray.yorksj.ac.uk/id/eprint/4679/

The version presented here may differ from the published version or version of record. If you intend to cite from the work you are advised to consult the publisher's version: http://dx.doi.org/10.1016/j.annals.2015.11.011

Research at York St John (RaY) is an institutional repository. It supports the principles of open access by making the research outputs of the University available in digital form. Copyright of the items stored in RaY reside with the authors and/or other copyright owners. Users may access full text items free of charge, and may download a copy for private study or non-commercial research. For further reuse terms, see licence terms governing individual outputs. Institutional Repository Policy Statement

\title{
RaY
}

Research at the University of York St John

For more information please contact RaY at ray@yorksj.ac.uk 


\section{THE TOURISM KNOWLEDGE SYSTEM}

John Tribe, University of Surrey, UK.

Janne J. Liburd, University of Southern Denmark, Denmark

\section{Abstract}

This conceptual study addresses the significant need for every mature field of knowledge to understand itself. It builds upon previous studies of the epistemology and ontology of tourism by critiquing, synthesising, discarding, re-ordering and adding material. Its contribution is an original reconceptualisation of the structure, systems, processes and outcomes that define the field of tourism. These are explained by the creation of a model and detailed analysis that examines knowledge space, the knowledge force-field, knowledge networks, four key domains in knowledge creation and their interrelationships. Finally the model is used to examine some of the key challenges and consequences that the knowledge system reveals for tourism and its research.

\section{Keywords}

Epistemology, Knowledge System, Reconceptualisation, Selectivity.

\section{Introduction}

The rationale for this article is taken from Kuhn (1962, p. 209) who concludes his analyses of progress in science knowledge "by underscoring the need for a similar ... study of the corresponding communities in other fields" (p.209). There have been various studies examining tourism knowledge commencing with Jafari and Ritchie's (1981) wheel of knowledge. The subject resurfaced when Echtner and Jamal (1997) reviewed the existing state of debate and Tribe (1997) outlined his "Indiscipline" thesis. Tribe twice revisited this theme, first in 2006 where he identified the force-field that operated on truth telling, and later in $\mathbf{2 0 1 0}$ where he combined Actor Network Theory with an epistemological and cultural enquiry. Meanwhile Coles, Hall and Duval (2006) discussed what postdisciplinarity (Sayer, 1999) might mean for tourism studies, Belhassen and Caton (2009) offered a linguistic approach to understanding tourism epistemology, Liburd (2012) examined the pluralist epistemology offered by Web 2.0 technology and Laws and Scott (2015) use the metaphor of a mosaic to portray tourism research. But each of these studies provides only a part of the jigsaw and some are now somewhat dated so this article will seize the opportunity to critique, synthesise, update and add significant parts that are missing from previous analyses.

Accordingly, the aim of this study is to critically evaluate and reconceptualise the epistemology and ontology of tourism by developing a comprehensive model of the tourism knowledge system. Its first objective is to understand and portray the major parts of the system which are the phenomenal world of tourism, modes of analysis and its representations. The second objective is to analyse the inter-relationships, processes and 
dynamics of the system and the final objective is to consider critical consequences and new agendas. The main body of the article will outline the method and briefly review the key literature before presenting the model and elaborating on the objectives outlined above. The final section will discuss conclusions.

\section{The tourism knowledge system}

\subsection{Method}

This article follows the protocols outlined by Xin, Tribe, and Chambers (2013) for conceptual research, mindful of the lack of explicit method evident in many conceptual papers. But equally we are aware of the need to avoid any methodological strait-jacketing and remain open and creative in our thinking. In broad terms we follow a process of scoping, comparison, reflection and abstraction. This is followed by a number of steps including defining concepts, comparing them, historical analysis, the construction of conceptual typologies, finding conceptual gaps, deep reflection, synthesising and finally a reconceptualisation of the subject.

We also address the quality conditions for conceptual research (specified in brackets). First, the argument is based on the authors' expertise, long term engagement with the issues and deep knowledge of the relevant literature (good scholarship). Second there was systematic evaluation of counter evidence and a Socratic dialogue maintained between the authors (soft falsification). Third careful attention is paid to the structure, logic and plausibility of the argument (rhetoric). Fourth the argument is compared with established neighbouring concepts (triangulation). Fifth the results are consistent with the research aims (validity). Sixth the research process is carefully documented (transparency). Seventh the results add to human understanding (usefulness). Eighth, the results make something visible that was previously not so (additionality). The final condition (reflexivity) requires a short discussion. The authors are male and female, senior, white, northern European academics. The nature of this article demonstrates that embodied, structural and other considerations will influence the conduct of our research too. Additionally our lifelong immersion and participation in a particular epistemological project (the academy in its Western tradition) inevitably influences our gaze on and approach to this research topic. We note this so that readers can be alert to our positionality but also to remind ourselves that we need to make a special effort to understand and not to "other" "other knowledge" including its tacit, informal, experiential, oral, moral, practice, indigenous and other dimensions.

\subsection{The sociology of knowledge}

A brief recap of the key literature of the sociology of knowledge reminds us that knowledge is socially conditioned (Barnes, 2014) and offers a critical understanding of how the tourism knowledge system is constructed and the consequences of this. There are several notable issues. The role that ideology plays in the production of knowledge was a major interest of Mannheim (1979). Berger and Luckmann (1991) analysed what they termed the social construction of reality whereby concepts become habituated as is people interact in a social system and that over time through reciprocal interactions they become institutionalized. 
Merton (1937) examined the role of institutional settings of scientific research in conditioning the creation of scientific knowledge. Kuhn (1962) emphasised the importance of research communities and their established norms and paradigms in the construction of knowledge. Becher's (1989) sociological investigation of Academic Tribes identified a spectrum of cultures that influenced knowledge production in different disciplines. Foucault (1971, 1974, 1980) introduced the ideas of discourse, disciplining, surveillance and power, describing discourses as 'regimes of truth'. Discursive formations provide the rules for what counts as knowledge and what does not and further who speaks with authority and who does not. Habermas (1978), through his theory of knowledge constitutive interests, demonstrated that the pursuit of knowledge is not interest-free but motivated by one of three interests. First, the technical interest seeks management and control. Second, the practical interest seeks understanding and third, the emancipatory interest seeks freedom from falsehood and emancipation from oppression. Hence different interests would promote different knowledge. Lyotard (1984) noted a preference for knowledge which is useful to the economy concluding that "the goal is no longer truth, but performativity - that is the best possible input / output equation" (1984: 46). All of these theories have consequences for understanding the tourism knowledge system - its knowledge production; its encoding; its transmission; receptivity to and decoding of knowledge; its storage; its retrieval and the construction of its canon.

\subsection{Extending indisciplinarity}

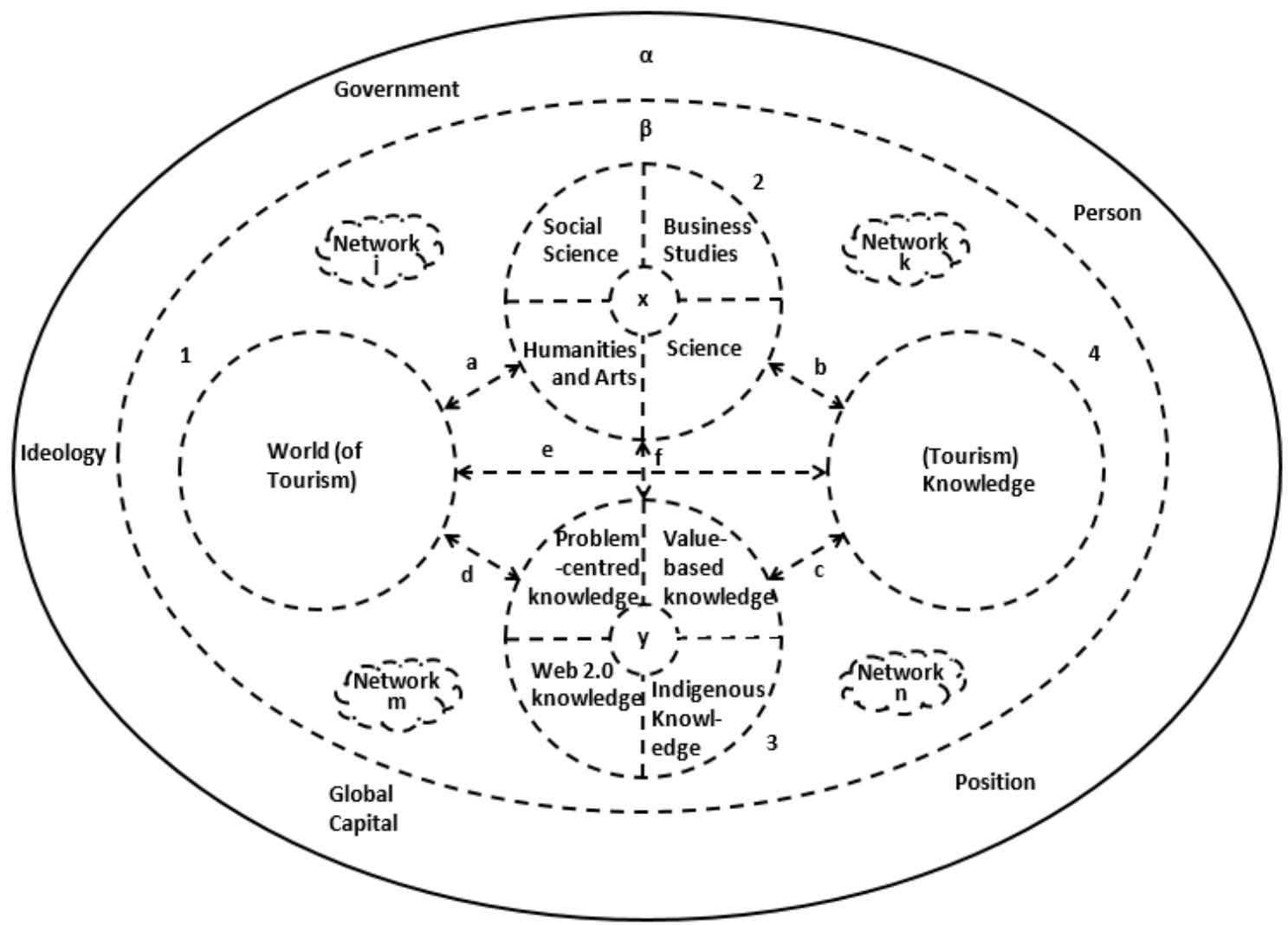

Figure 1 The Tourism Knowledge System 
The reconceptualised tourism knowledge system is presented in figure 1 . The model demonstrates a number of generic features of systems, which consists of interacting parts and complex, dynamic relations (Anderson, 2013). It identifies a set of elements that form a meaningful and coherent whole in relation to the epistemology and ontology of tourism and maps the relationships between these elements. The system comprises inputs (circle 1) and outputs (circle 4), processes (circles 2 and 3 ), boundaries (inner oval $\beta$ ), environmental factors (outer oval $\alpha$ ) and feedback loops (e.g. line e).

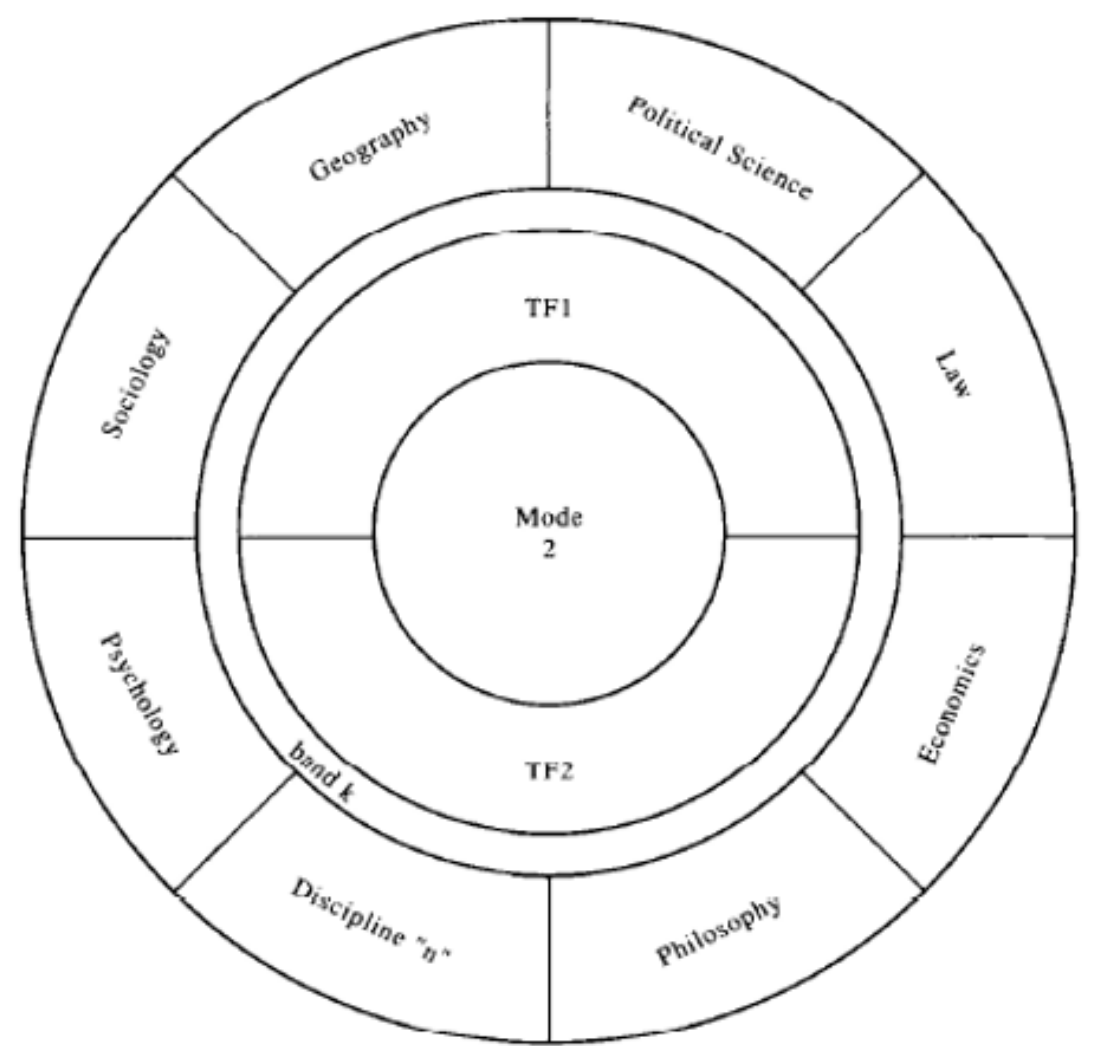

Figure 2. The Creation of Tourism Knowledge. Outer Circle=Disciplines and Subdisciplines; Middle Circle $=$ Fields of Tourism; Inner Circle $=$ World of Tourism; TF1=Busincss Intcrdisciplinarity; TF2=Non-Business-Related Tourism

We proceed with a brief critique of the key previous models. Jafari \& Brent Ritchie's (1981) Wheel of Knowledge provided a useful assembling of the key subject areas of tourism but as a descriptive account it lacks any deeper analysis of processes, products or producers of knowledge. Next, The Indiscipline of Tourism (Tribe, 1997) (figure 2) depicted tourism as two fields of study - TF1 (the business of tourism) and TF2 (the non-business of tourism). It further demonstrated the multi- and inter-disciplinarity of tourism as well as making the important distinction between Mode 1 and Mode 2 knowledge where the former is produced inside the academy while the latter is produced outside of it.

We note that the terms TF1 and TF2 are somewhat clumsy and have not much entered the lexicon of tourism knowledge system. In fact we have never heard anyone mention them! 
Our original solution was to re-interpret these two fields as the Business of Tourism and the Social Science of Tourism but after further analysis we have elected to extend these to encompass the full range of disciplinary groupings by which tourism can be analysed. Hence in figure 1, circle 2 is divided into the four major disciplinary groups of Business Studies, Social Science, the Humanities and Arts, and Science. An interdisciplinary space is maintained in circle 2 as the inner zone $x$ and facilitated by the use of dotted rather than solid lines of demarcation. The whole of circle 2 now represents the site of disciplinary (mode 1 ) knowledge production which broadly coincides with the boundaries of the traditional academy and represents a space which is highly theoretical and governed by disciplinary rules.

\subsubsection{The disciplines of tourism (Circle 2)}

\subsubsection{Social Science and Business Studies}

These aspects of tourism knowledge production are well covered in the literature and so will not be discussed in great detail. The social sciences are represented by economics, geography, sociology, anthropology, psychology, political science and law. These disciplines have been fundamental to the creation of tourism as an academic field and social science research endeavours are relatively open in their inquiry into how tourism can be known.

The business studies of tourism represent vocational areas of operation, such as marketing, finance, human resource management, service management, destination planning, ITC and innovation. There is considerable permeability between social sciences and business studies as tourism's key concerns include understanding tourists, tourism businesses and tourism's economic, social and environmental aspects. Both the social sciences and business studies of tourism enjoy systematic privilege in tourism studies (Aramberri, 2010; Butler, 2015).

\subsubsection{Humanities and the Arts}

The humanities and arts include philosophy, history, language, literature, communication, design, music, dance and art among others, and concern human expression and the study of culture. They offer the ability to critique tradition, the status quo, and the ideas of oneself and of others (Barnett, 1994). Collini (2002) reminds us that cultural criticism signifies the movement of artistic and intellectual work outward, towards society (p. 91). It is only 'towards' society as the humanities and arts generally avoid entering into the politics of society and are rarely influential in shaping politics. Rather they are intellectual activities that help prompt critical reflections on aspects of life that the politics and practice of everyday life do not readily foster (Collini, 2002).

Humanities and arts can critically address tourism as a complex, world-making phenomenon and practice through which (inter-) cultural understandings and expression unfold. Encouraging imagination, empathy and resistance, they stimulate understandings of virtue, beauty, and our desire to create better futures (Liburd, 2013). Their deep reflection on the bigger questions in life, for example - What does it mean to be human (a tourist)? What constitutes a good life (for tourism)? What is a just (tourism) world? - enjoy a long trajectory 
in Western philosophy (Caton, 2014). Progress in the humanities and the arts in tourism is limited but has had some success through the development of specialist journals such as the Journal of Tourism and Cultural Change and the Journal of Tourism History. The latter has signalled the importance of "historical geographers .... strong links to heritage studies ... , themes in histories of politics ..., diplomacy, demography, labour and gender studies, and economic development" (Walton, 2009, p. 1).

A recent example using arts in tourism research is the work by Rydzik, Pritchard, Morgan and Sedgley (2013) who explore the journeys and experiences of a group of female migrant tourism workers. This arts-based participatory method resulted in migrant trajectories, mobilities, identities and employment experiences being represented in paintings, photography, glass fusion, poetry, and other forms of artistic expression. The work offers voice and visibility to marginalised workers and provides insights that promote empowerment and research collaboration that hold transformative potentials.

Mindful of the limitations of the social science and business of tourism to create imaginative futures, the humanities and the arts offer the potential to provide deeper understandings of past, present and future visions of tourism.

\subsubsection{Science}

Science includes the 'hard' disciplines of medicine, biology, physics, chemistry, psychology, mathematics and engineering characterised by positivist rules and procedures. They have a unique and often globally applied potential to offer solutions to major human and societal issues. For example medical research provides diagnoses to maintain and restore health through prevention and treatment of illness. Significant advances in medical research related to tourism are vaccines, improved treatments for HIV/AIDS, and treatments for cancer caused by sun exposure.

As an illustration Rojas, Malow, Ruffin, Rothe and Rosenberg (2011) examined HIV/AIDS epidemiological data in in the Caribbean. They identified tourism as a key contributing factor to the HIV epidemic, alongside poverty, illiteracy and low risk perception. They provided recommendations for governance in sustainable HIV prevention. Another example, demonstrating psychological research into well-being through tourism, examines the advantages of prescribing tourism to reduce stress and cardiovascular disease (Filep, 2014).

Also in science engineers provide insights into diverse tourism issues of aircraft design and sustainable building solutions. Physics, chemistry, biology, technology and nanotechnology research also advances progress in intelligent systems. These are used by tourists in online search and travel decision making enabling communication with the environment while continuously determining their favourability (Gretzel, 2011). Additionally Hall (2015) alerts us 
to the importance of understanding tourism's role in causing biological exchange and its implications for health and the environment.

We note that research engagement with the hard sciences is underdeveloped in the academic analysis of tourism. For example climate change and sustainability are more deeply engaged with as a social science rather than pure science issues and Butler (2015) points to a lack of research on environmental aspects of tourism. Further the scientific study of tourism is disconnected from the main body of the tourism academy and often happens outside of it. For example the study by Qiuyun et al. (2011) on the carrying capacity of tourism water resources in the Hainan Province is published in their home discipline journal of Systems Engineering Procedia. This point is further supported by Bauer (2015) in the Journal of Travel Medicine who notes that the medical literature fails to engage with tourism research.

\subsubsection{Zone X: Interdisciplinary}

Zone $X$ in circle 2 illustrates the potential of interdisciplinary tourism research (Darbellay \& Stock, 2012). Klein (2012) defines interdisciplinarity as: "a synthesis of ideas, data and information, methods, tools, concepts, and/or theories from two or more disciplines aimed at answering a complex question, solving a complex problem, or producing new knowledge or a product" (p. 6). Interdisciplinary research is predicated on the freedom to explore using any theory or method. This includes extra-disciplinary and non-scholarly approaches to relate any set of materials deemed of relevance by the researcher to the process of inquiry (Repko, 2008; Szostak, 2012). An example could be engineering, nanotechnology and textile design merging to co-create smart wear, or intelligent soft mobility systems for tourism.

\subsubsection{Extra-disciplinary tourism knowledge (Circle 3)}

Our further deconstruction of The Indiscipline of Tourism revealed that it had been too narrow in its understanding of knowledge creation and too obtuse in naming its parts. Accordingly we have renamed mode 2 as "Problem-centred Knowledge" and relocated it to circle 3 which represents tourism knowledge produced outside traditional disciplines. We label circle 3 as "extra-disciplinary tourism knowledge" and extend it to include Value-based Knowledge, web 2.0 and indigenous knowledge.

We should pause briefly to address the issue of postdisciplinarity introduced by Sayer (1999) and Coles, Hall, \& Duval (2006). We understand postdisciplinarity as an effort to escape the possible over-disciplining of disciplines and the negative effects of their rigid boundaries and theoretical natures and instead allowing the problem to define a more eclectic and practical approach to the solution. But we do not see postdisciplinarity as something much different from interdisciplinarity (zone $\mathrm{x}$ ) combined with Problem-centred Knowledge. However it does lead us to reflect that the Indiscipline model portrayed mode 1 and mode 2 as binaries and it would be better to stress the fluidity between mode 1 and mode 2 . This is accommodated in figure 1 by the use of dotted lines denoting permeability between the segments in and across circles 2 and 3. 


\subsubsection{Problem-centred Knowledge}

Ingold (2013) offers a radical critique of hard science arguing for an epistemological shift where knowing is 'understanding in practice' and wishes to assign disciplines (in his case anthropology) a greater role in the world and its making. He urges us to develop our knowledge of the world from the inside as co-creators with other beings and things and engage with making. Ingold's making is morphogenetic and involves entering "the grain of the world's becoming and bend it to an evolving purpose" (p.4). As noted above, we label this domain as "Problem-centred Knowledge" (sometimes called mode 2 knowledge, or knowledge in practice) which is knowledge in and for the world. It is highly contextualised (Hessels \& Van Lente, 2008) relating to specific projects, whether by industry, government or society in more general terms. Problem-centred Knowledge is generated within the context of application. Its dominant interest is the technical one of solving practical problems. Problem solving often relies on tacit, experiential knowledge by those engaged in the doing and making of tourism, such as consumers, providers and the community. Tacit knowledge is often taken for granted and overlooked. Further the transfer of tacit knowledge generally requires oral as opposed to written exchange based on close interaction and trust (Polyani, [1966] 2009). Liburd (2007) explains how tacit cultural practices among traditional Danish inn owners were revealed through storytelling, which facilitated pride, staff retention and competence development.

Mobilising a range of theoretical perspectives and practical methodologies, Problem-centred Knowledge is extra-disciplinary. Unlike inter- or multidisciplinarity, it does not necessarily derive from other disciplines, nor contribute to disciplinary knowledge. Its intent is understanding and changing existing practice. It is therefore governed by a functionalist epistemology in search of useful and efficient knowledge with a focus on application (Gibbons et al., 1994).

Examples include reports by the UNWTO, industrial R\&D, industry PhDs, intermediaries such as tourism planners, consultants, DMOs, NGOs, charities such as Tourism Concern, as well as governmental research, including OECD reports and the applied research agendas pursued by research councils. All of these open up a wide array of socio-economic and scientific issues and problems that are best solved by context-sensitive approaches and solutions.

Part of the legacy of the Australian Sustainable Tourism Cooperative Research Centre (STCRC) is a testament to Problem-centred Knowledge. During more than a decade (1997-2010) STCRC (2010, p. 31) research was driven by government, industry, and institutional competitive grants operating with a budget of AU\$266 million. The STCRC sponsored the successful completion of more than 150 tourism industry-related PhDs. Strategic, context-driven research outputs were published in more than 450 technical and industry reports and in the form of industry-specific toolkits. 
However Problem-centred Knowledge does encounter problems. Finding the most adequate solution for a practical problem may eliminate complexities and create repercussions, loose ends, and unforeseen consequences (Barnett, 2004). It may also be that many Problemcentred Knowledge solutions are hindered by unintentional biases stemming from their initial contextualisations. In other words it is not as "dis-interested" as mode 1 knowledge.

\subsubsection{Value-based knowledge}

Feyerabend (1975), in his work Against Method, sets the scene for developing the next segment in circle 3 when he states that that we should not allow disciplinary knowledge that has an objectivity obsession to rule unchallenged. He asks:

"is it not possible that science as we know it today, or a "search for the truth" in the style of traditional philosophy, will create a monster? Is it not possible that an objective approach that frowns upon personal connections between the entities examined will harm people, turn them into miserable, unfriendly, self-righteous mechanisms without charm or humour? ... I believe that a reform of the sciences that makes them more anarchic and more subjective ...is urgently needed..." (p.127)

Our reform draws on Heidegger's notion of being which is a matter of "being-possible" (Heidegger, 1962, p. 183) and emphasises how being is a matter of becoming, encompassing change, unfolding potentials and asking "becoming what?". These issues have been discussed by Platenkamp (2007) and others under the heading of mode 3 knowledge. However we prefer to use the term "Value-based Knowledge" (or moral knowledge) which is more directly descriptive and we incorporate this in circle 3. Value-based Knowledge harnesses the importance of values and meaningful interpretation. It engages human qualities and dispositions, authentic presence and meaningful participation in the context of world-making. Hard disciplinary knowledge has objectivity and value neutrality at its core, but Value-based Knowledge puts values at the heart of the project, as advocated by Caton (2012). Its focus might be for example tourism for equality, or for peace and has been advanced by Pritchard, Morgan, and Ateljevic (2011) in the form of Hopeful Tourism. We would add standpoint research such as feminist or Marxist research as further examples of Value-based Knowledge. Its inclusion compensates for the lack of existential or ontological awareness or possibilities in the analysis offered by The Indiscipline of Tourism.

We offer two insights into Value-based Knowledge. First Veijola et al. (2014) seek to shake free from tourism's conventional epistemology and ontology. They pursue this in an unusual laboratory - a writing camp in Finnish Lapland - where they "begin in the middle of things" (p.7) to promote "disruptive tourism". They "camp within and across territories of academic theorizing" wanting "to stir political and ethical imagination in envisioning alternative ways of being" (p.9). They seek to break the rules of conventional knowledge production by invoking virtual philosophical houseguests, travelling across disciplinary boundaries, using a 
free narrative style, positioning tourism as an agent of change and being reflexive about their sharing of thinking. They configure "alternative ontologies of tourism to the ones that take reality to exist through clear-cut and self subsistent beings, subjects and categories" (p.4). Rather their focus is on messiness and "potentialities of being with other people" (p.4), taking

" 'withness' or togetherness as the ontological starting point of ... tourism" (p.4). They argue that this type of disruption of the habitual in tourism and its scholarship may lead to new understandings of the good life.

Second Grimwood (2014) argues that "tourism perceptions and representations of the Arctic as remote, pristine 'nature' - common in tourism discourses linked to colonialism and Western visions of modernity - conceal Aboriginal inhabitants" (p.18) and thereby their voice and interests. Grimwood wishes to confront this ontological essentialism of the pristine Arctic using an approach based on co-operative values. He approached his case study site - the Thelon River - axiologically, ontologically and epitemologically aware, labelling it as as a moral terrain. In doing so his "conceptual/theoretical intention was to jar totalizing systems of value (i.e. dominant narratives of nature) with indeterminate, permeable and collective alternatives" (p.5) usinig metaphors. His mobile ethnography of canoeists and Inuit inhabitants "illuminated three relational, value-based metaphors [emplacement, wayfaring and gathering] that eschew ontologically pure and divisive categories like nature." (p.18). Emplacement is how "people, things, ideas, meanings, histories and landscapes converged to enact place" (p.18). Wayfaring is travel that actively engages with the environment. Gathering is a coming together. These metaphors are not static but "convey fluid, ambiguous processes of becoming, connection and participation." (p.18).

Engaging with dynamic, reflexive, value-engaged scholarship in tourism (Hollinshead, 2006) offers the potential for open, ontological and experiential collaboration that involves civic society, government, industry and tourism academics seeking to discover what might be.

\subsubsection{Web 2.0}

There are two further types of knowledge creation overlooked in The Indiscipline of Tourism. The first is web 2.0 knowledge which according to Liburd (2012) refers to the philosophical principles and social practice of sharing of information and knowledge by users generating, altering and uploading web-based content (p.890). Web 2.0 knowledge stems from new technologies, connections, institutions, networks and practices with other forms and norms of knowledge (Liburd, 2012). In contrast to passive viewing and downloading of largely copyrighted information web 2.0 refers to the principles and practice of facilitating information sharing and social interaction by users generating, altering and uploading webbased content (O'Reilly, 2005).

The idea of web 2.0 knowledge as a process and activity and a community of practice differs from disciplinary knowledge as a state or disposition acquired by the individual. Thriving on a 
pluralist epistemology, knowledge production is a matter of continuous reflexivity of the producers, acquirers and users. Web 2.0 thrives on multi-, inter- and extra-disciplinary knowledge by a network of actors who form a coalition of participants working together on a common task. Creating a demand-pull as well as a supply-push for knowledge, research is exchanged within and across different domains enabled by tools such as blogs, wikis, social networks and open access. Web 2.0 activities are characterised by a bottom-up production and negotiation of meaning by collective intelligence and by the continuous application, reuse, and transformation of material across contexts.

An example of web 2.0 in marine tourism is Ecocean which is dedicated to non-invasive research and preservation of whale sharks. In collaboration with NASA scientists Ecocean developed a method for visual recordings of whale shark sightings from around the world. Existing techniques from NASA's Hubble Space Telescope for mapping star patterns, known as the Groth algorithm, were adapted for use on living creatures (Hughes, 2008). A reliable way of identifying individuals in any uniquely spotted animal population was established. Data in the form of tourists' whale shark photos are continuously uploaded to the designated website for tracking and research purposes.

The example illustrates how web 2.0 research is conducted by contingent groups of otherwise unrelated participants. An important ontological aspect of web 2.0 knowledge creation is that the traditional Cartesian view of knowledge, "I think therefore I am" (disciplinary knowledge) is complemented by a social view that "we participate therefore we are" (Liburd, 2010, p. 893). We note how web 2.0 facilitates transformation from closed and controlled tourism research through communicative action, critical engagement, and open collaboration. Further, ownership through copyright law is surrendered to the end users by removing or modifying copyright restrictions by copyleft licensing. A copyleft example is the Creative Commons that allows for legal distribution of copies and adapted versions of the work of others while acknowledging the original author(s) and requiring that the same freedoms be preserved in future versions (Berry, 2008).

Web 2.0 enables other ways of knowing through open collaboration so permeability with Problem-centred Knowledge, Value-based Knowledge and indigenous knowledge is also possible. However we have found scarce evidence of web 2.0 in tourism research that openly shares knowledge to co-create understandings, interpretations and related publications.

\subsubsection{Indigenous knowledges}

The final lacuna addressed in circle 3 is indigenous knowledges. This refers to knowledge originating from specific cultural, geographical and traditional circumstances that are ontologically tied - not only to - but within the self (Picard \& Di Giovine, 2014) a specific community (Schellhorn, 2010) and postcolonial perspectives (Chambers \& Buzinde, 2015). Often embedded in oral traditions, indigenous knowledges are passed on from generations 
through cosmologies, diaspora, storytelling, arts, crafts, spirituality, language and classification systems. The explicit inclusion of indigenous tourism knowledges in this system offers a site of resistance against possibilities of marginalisation, exploitation and oppression in tourism which may be at the hands of nation states, or politically dominant ethnic groups that are actively or passively legitimized by the more established forms of knowledge production.

We acknowledge the contested definition of indigenous and refer to the United Nations' definition of indigenous people as those who were present before colonisation, i.e. present and occupying a given area before the formation of modern nation states and borders. Indigenous knowledges are deliberately addressed in the plural to avoid the privileging of any specific body of knowledge, practice and beliefs. Indigenous knowledges embrace the essence of ancestral knowing as a complex accumulation of context-related knowledge, legacies of diverse stories and cultures by cultural transmission, the dynamic relationships of living beings with each other and their environment (Akena, 2012). Indigenous knowledge includes many norms and forms of knowledge, often learned through traditional subsistence (e.g. technologies, materials, botany, ecology, navigation, the climate) or encounters with tourism and tourists. Evans-Pritchard (1989) provides an insightful narrative of how tourists' stereotypes of Native American Indians are manipulated to help empower an indigenous minority. Often labelled as inferior, superstitious, backward and suppressed by Western knowledge, respecting indigenous knowledge represents a 'speaking back' to the power, production, categorization, marginalised and oppressed position of non-Western cultures, identities and histories (Dei, 2008).

Since the publication of the seminal Tourism and Indigenous Peoples (Butler \& Hinch, 2007) a growing body of indigenous tourism research has addressed the business of indigenous tourism, economic independence, ecology and environmental stewardship, cultural rejuvenation, cultural degradation, acculturation, and hegemonic subjugation. Chambers \& Buzinde, (2015) argue that tourism knowledge is still predominantly colonial through its production and dissemination by former colonial powers and that superiority is attributed to disciplinary knowledge especially that obtained via the scientific method. 'Other' forms of knowledge acquisition that do not use the scientific method are viewed as inferior and untrustworthy. Smith and Sharp (2012) found this particularly evident in climate change research whenever explanations of environmental or behavioural conditions are expressed in terms of spiritual intervention or phenomena (p. 469).

Finding "a dearth of evidence of decolonial critique emanating from tourism scholars and practitioners in and from the South" Chambers and Buzinde $(2015$, p. 8) propose a new agenda for tourism's epistemological decolonisation. To enable further understandings from the perspective of local and indigenous epistemologies of tourism to emerge they call for 
psychological liberation, transformation and educational integration of native knowledges and practices emanating from scholars from the South whose language is not English (p. 10). Noting the under representation of indigenous peoples themselves in indigenous-driven research (Nielsen \& Wilson, 2012), we refer to Amoamo (2011) as an exemplar. Amoamo explores how Homi Bhabha's (1990) concept of new-sense unsettles fixed identities to empower new, third space visions and subjectivities for indigenous people. Being a Maori researcher, she explains how expressive and transient identity images challenge tourism's propensity to label and make serviceable those 'others'. Probing the emergent identities of cultural production for concepts such as hybridity, she reveals the ambivalences and ambiguities of the new in-between forms of culture and difference. Indigenous knowledge is also used to generate competitive advantage in Australian tour operations. Offering "revelatory tours" through the physical landscape, Nugal-warra family elders provide unique insights into Aboriginal spirituality, culture, rock art and bush medicine in their daily lives and interactions with tourists in the Northern Territory (Guurrbi Tours, 2015).

We have still to see more representations of indigenous tourism knowledges, including explorations of how indigenous knowledges are valued in authentic being, justice, wisdom, and the fusion of epistemology and ontology.

\subsubsection{Zone Y: the extra-disciplinary mix}

Zone $Y$ offers a space for the convergence of Problem-centred Knowledge, Value-based Knowledge, web 2.0 and indigenous knowledges where each is directed and received by each toward and for the other. It offers a highly participatory, democratic, practical and mutual mixing space for tourism knowledge with hitherto unexplored potentials. Offering an ethical, creative space and support for new academic engagements, the unique blends of contextspecific, industry related, open, experiential and indigenous research should pose questions and seek answers that can move in profoundly new and different directions. Some of the opportunities of this zone are discussed by Wilson and Hollinshead in their article on "soft science" (2015).

Taken together the reconfigurations, reorganisations and the identification of additional knowledge spaces outlined above enable significant modification to The Indiscipline model so that it is now expanded to become circles 2 and 3 in figure 1. However a further shortcoming of the Indiscipline is that it presents a static model so to address this we now turn to The Truth about Tourism (Tribe, 2006), reproduced in figure 3, to help us understand the dynamics of the tourism knowledge network. 


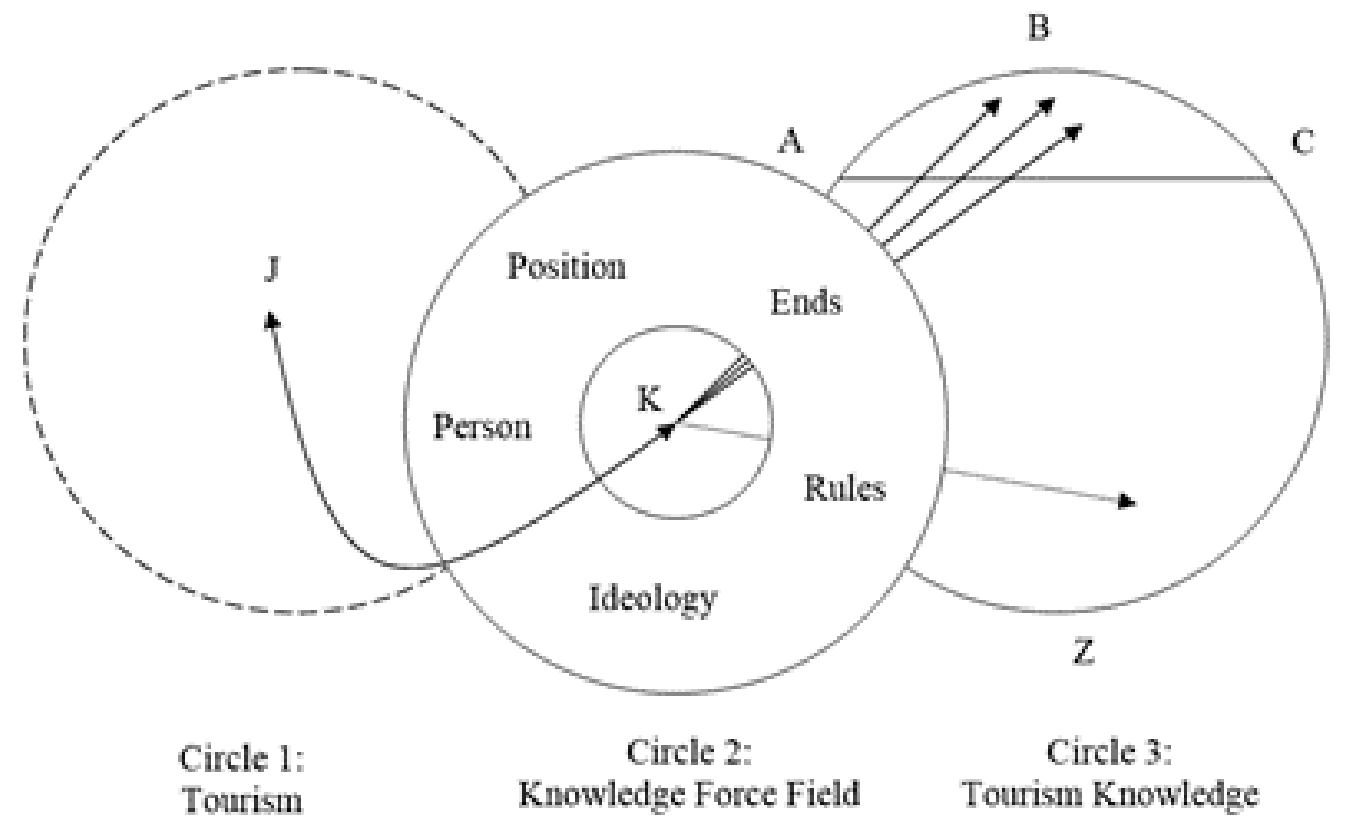

Figure 3 The Truth about Tourism

\subsection{Beyond "the truth"}

Deploying Tribe's (2006) Truth about Tourism brings two important dynamics to the development of our new tourism knowledge system. First it extends its remit beyond that of the Indiscipline of Tourism which was limited to questions of knowledge production. It does this by relating the production of knowledge (circles 2 and 3 in figure 3) ontologically to the world that it is researching (circle 1) and rhetorically to the canon of knowledge which is produced (circle 3). It therefore provides the dynamic pattern to connect the basic building blocks of our tourism knowledge system (circles 1 -4). This knowledge system revealed for Tribe (2006: 375 ) a double selectivity at work. The first selectivity arises as the researcher's gaze falls on the world of tourism. It is about what is seen and unseen. The second selectivity concerns the processing of knowledge of the world of tourism. Researchers choose their analytical strategy from a range of modes. We will build upon this later as our model is further developed.

The second contribution of The Truth about Tourism was to invoke the sociology of knowledge to demonstrate the existence and effects of a knowledge force field on the production of tourism knowledge. Figure 3 illustrates these forces as person, position, ends, rules and ideology demonstrating that knowledge production is never purely objective, nor value or interest free but rather is subject to a range of sociological forces. Next we review these forces and modify and integrate them into the outer band $\alpha$ of our tourism knowledge system model which represents the revised knowledge force-field.

\subsubsection{Person}

We include "person" in band $\alpha$ of our system noting two important aspects. First as researchers we cannot escape our embodied selves (Crouch, 2000). Despite the Cartesian 
dualism of mind and body and the striving of positivism for objectivity, our minds reside in our bodies (Merleau-Ponty, 1962). Amongst other things our bodies carry with them our autobiographies, our socialisations, our cultures, our genders, our sexual orientation, our instincts, our senses, our values. Each of these necessarily influences our research. However we wish to note a point overlooked by Tribe, which is the positive power of agency (Giddens, 1984) or the capacity of individuals to act independently and exercise free choice despite structural arrangements which influence or limit the choices and opportunities available.

\subsubsection{Ideology}

Similarly "ideology" is incorporated into band $\alpha$ as an important element in the knowledge force field. Althuser $(1969 ; 1984)$ and Apple (1990) alert us to ideology as a set of common sense beliefs which are unreflexively ingrained in our thought and guide our practice. Further, Gramsci (1971) points up a hegemonic tendency where the ideology of the ruling class dominates thought and action suppressing competing ideologies. We note here the hegemonic influences of the ideology of Western capitalism, neoliberalism and consumerism as powerful forces shaping tourism knowledge production (Tribe, Dann \& Jamal, 2015). We further note that tourism itself is an ideological project (see above Grimwood's critique of the Arctic tourism being "situated within fields of power that, historically, operate to favour certain knowledges, practices and values, while disenfranchising others." (p.2) ). We also note that value-based positional research such as feminist (Gunew, 2013) or postcolonial research can offer an important counter force to that which conforms to the dominant ideology.

\subsubsection{Position}

Tribe (2006) explains "position" as encompassing geographic location, university department as well as academic, language and cultural communities and explains how this force can lead to "ethnocentricity, departmentalism and academic tribalism" (p.370). The importance of "position" means that we wish to incorporate this force in band $\alpha$. But we must also concede that some aspects of "position" are already accounted for in circles 2 and 3 which display for example alternative positions of science vs social science and disciplinary vs Value-based Knowledge and indigenous knowledge.

\subsubsection{Rules and Ends}

Within his category of "rules" Tribe encompassed academic rules, discourse and paradigms. We wish to bring some conceptual clarity here and argue that in our tourism knowledge system we do not need to portray rules as a separate category in band $\alpha$. Rather the elements of academic rules and discourses belong in circles 2 and 3 and the broader philosophical idea of paradigms sits better with "ideology". Similarly we do not feel the need to identify "ends" as a separate category in band $\alpha$. We just need to note that knowledge formed in circle 2 is most likely to have intrinsic ends as knowledge for itself. While in circle 3 Problem-centred Knowledge is most likely to signal the production of "useful" knowledge and Value-based Knowledge the production of knowledge to advance specific values. 


\subsubsection{Government}

We have rationalised Tribe's five forces to three but argue that he overlooked two important forces that should be added to this system. The first of these is government. Governments no longer leave universities to follow independent paths. They seek to set agendas through their financing of research and through the goals set by research councils. The European Union's Horizon 2020 is a good example. This programme will allocate 80 billion euros for research linked to its key goals which include excellent science, industrial leadership and societal challenges. On a more critical note Collini (2012) points to a new government inspired Holy Trinity of impact, assessment and funding that privileges realism, being up-to-date and competiveness. Additionally governments often directly fund and steer Problem-centred Knowledge initiatives to further their policy aims.

\subsubsection{Global Capital}

Finally we argue that "global capital" is a significant force in this system. While the ideas of neoliberalism and capitalism are covered under "ideology", global capital has a significant material dimension too. First global capital has constructed the material things of tourism such as airports and resorts and as Turkle (2007) notes things have the power to bend thoughts and actions towards them. Second global capital exerts its direct power through money and its indirect power through influence.

In conclusion to this section band $\alpha$ in figure 1 illustrates the elements of our modified force field comprising the five forces of person, position, ideology, government and global capital. The point about the force field is that it mounts a serious challenge to the notion of interestfree research in tourism demonstrating the extent, power and effects of key forces that shape and mould it.

\subsection{Knowledge networks}

In Tribes, territories and networks in the tourism academy, Tribe (2010) incorporated actornetwork theory (ANT) (Callon, 2001) and the mobilities paradigm into the analysis of tourism knowledge. He did this in order to understand the importance of human and non-human agents, to examine the blurring and interconnectedness evident in the field and to understand the process by which it is constantly being re-configured. Tribe (2010, p. 23) conceptualized part of tourism studies in terms of "actors and a series of overlapping networks that are in constant flux-circulating, becoming, dissolving, merging and demerging." Following Ren, Pritchard and Morgan (2010), and to capture the fluidity, flux and mobility of tourism research our model depicts networks as a number of exemplar clouds $(j-$ $\mathrm{n}$ in oval $\beta$ ) circulating around the system. These clouds contrast metaphorically to the fixity suggested by the rest of figure 1 . Clouds grow, they merge, they are fluid, they are full of movement, they float, they dissolve, they re-form.

Another important aspect of ANT is its encompassing of non-human as well as human entities so that an effective network in tourism knowledge production might consists of inscriptions 
(Barnes, 2001) such as books or articles, technologies such as the internet, conferences, people, buildings and institutions (Ren, et.al, 2010). By way of example we use the Critical Tourism Studies (CTS) network to illustrate cloud j. This started life as the Gender Research in Tourism Studies (GRITS) but through planned, unplanned and serendipitous discussions a process of problematisation scoped its new cause. Thereafter its primary actors embarked on a process of interessement - mobilising actors to the cause and enrolment to positions in the network and CTS established itself as a fully developed network at an inaugural conference in Dubrovnik 2005. The cloud metaphor neatly describes the network's development as primary actors left and were replaced, aims shifted, articles and books were published and the network morphed through different shapes through a series of biennial conferences. But the significance of networks to the Tourism Knowledge System is their fluidity and mobility, their ability to translate (Callon, 1980) new entities, relations and meanings and their power to create resistance and alternatives for individuals and groups whose agency seems blocked by the force field in band $\alpha$. These networks may be formal, informal and ad-hoc and include examples such as BEST EN, ATLAS, TRINET, TEFI, CAUTHE, ATHE and The Academy. Other networks may be activist groups such as Tourism Concern and Pro-Ams - amateurs who work to professional standards in new, distributed organisational groupings that are often networked by new technology (Leadbeater \& Miller, 2004).

\subsection{The world (of tourism) (Circle 1)}

Circle 1 represents the world of tourism to be researched not as an independent entity but interconnected and so it is depicted as a bracketed part of the wider world. A rough approximation of the tourism world is offered by Leiper's (1979) tourist system which comprises activities and phenomena in generating countries, destinations and the transit space between them. These include for example people, organisations, things, structures, effect, affect, objects and subjects. We also note here that there will always be phenomena that are not open to research and those that are of such complexity that they defy extraction from their context for research.

We also wish to draw attention to circle 1 not just as the starting point for research but also an end point. Here the world provides an audience and stage for tourism research which comprises for example academics, individuals, tourists, the industry, interest groups and governments. A closer analysis of this part of the world (of tourism) also discloses two more important selectivities at work. The first concerns which tourism knowledge is chosen for consumption. Here the research audience is faced with engaging or not engaging with research outputs. Shapiro, Kirkman, and Courtney (2007) used the term "lost in translation" to describe a gap in knowledge transfer where practitioners are disengaged from research published in academic journals by the esoteric way that knowledge is presented. Where engagement does occur a choice exists about which of the many outputs on offer to engage with. The second selectivity concerns how research is interpreted in the world. The reader 
inevitably brings personal interpretive frameworks to bear and so the meaning of research becomes a negotiated act between author and reader/user.

Research impact in the world takes two major forms. Pure academic impact is generally measured by citations, and results in works being re-circulated via circle 2 as an input into further research. But the full journey back to circle 1 involves non-academic impact. This has been defined as "an effect on, change or benefit to the economy, society, culture, public policy or services, health, the environment or quality of life beyond academia." (REF2014, 2011). This is research that bridges the gaps between the academic world and the world of practice. Here it is useful to revert back to the knowledge force field and note that in the UK the government, through its Research Excellence Framework, is seeking to encourage more of this type of practical research and less pure academic research. Shapiro et al. (2007) make a further interesting point here that much knowledge is "lost before translation" since practice end-users are often disinterested in the topic because they have had little input into the choice or design of research questions.

Pointing to impact in a more general sense Law and Urry (2004, p. 391) draw attention to the productive aspect of social inquiry and its methods stating that "they (help to) make social realities and social worlds. They do not simply describe the world as it is, but also enact it." This is what Hollinshead (2009) terms as 'worldmaking'. For example research on pro-poor tourism has not only developed a concept but the introduction and circulation of the concept has also led to new interventions by governments, businesses and by interest groups that have sought to include specifically pro-poor goals. In this sense some tourism research can be seen to be performative in that it produces the realities that it describes. We have the ontological paradox here described by Callon $(2006$, p. 7) where research is "outside of the reality that it describes and simultaneously participate[s] in the construction of that reality as an object by acting on it" Finally here we should note the potential (somewhat unfulfilled in tourism) of what Edward Said called public intellectuals who consciously position themselves in Circle 1 to promote the performative aspects of research by engaging with the world in its own language and through its popular media channels.

\subsection{Representations of tourism knowledge (Circle 4)}

We start this section by revealing another important selectivity at work. It is clear from figure 1 that there is a choice of what and how research is represented in circle 4 . Knowledge produced in circle 2 overwhelmingly populates circle 4 with standard items of academic output. These journal articles, conference papers and presentations, books and book chapters constitute the academic canon of tourism. But we wish to further investigate circle 4, and especially its unfulfilled potential first deliberating on the limitations of standard academic outputs and second understanding the outputs of circle 3. Xiao et al (2012) opened up a useful discussion on the first of these which we further develop here. The standard journal article has remained stubbornly unchanged over the last 300 years. We posit that this linear, literary 
form with standard sentences, paragraphs and common structure itself performs an unseen selectivity. That is that the final form (the journal article) might shape research that is undertaken to that which can fit its form. This is a classic case of the power of things (Turkle, 2007) (in this case the journal), or as Bauman might put it the journal hails its favoured research form (Bauman, 2000).

So what might this standard form be overlooking? Consider Thrift's (2008) work on nonrepresentational theory which has alerted us to "the ways in which the preconscious, subconscious or nonconscious playing out of life defies easy description and representation" (Xiao et al., 2012, p. 373). We use the example of affect and emotion (Anderson, 2013; Harrison \& Anderson, 2012) to illustrate what kind of things may be missed because of the power of journals to bound research. For example Buckley (2012, p. 965), when analysing rush and flow in adventure tourism noted that there is "an unexplored theme, that of the indescribable or ineffable experience known only to active participants ... Comparing my own psychological experience of rush, supported by that of co-participants, to the many previous theoretical concepts ... it became apparent that it is not the same as any of them." Buckley then grapples with finding a way to communicate this and decides to use vignettes to convey the emotional component through first-person accounts.

Clearly there is much opportunity in the academic representation of research in circle 4 to be much more creative, experimental and imaginative. Very little tourism research is represented using poetry, drama, painting, sculpture, opera, dance, installations, video, photography, performance or story-telling and it is surely the case that some of these would help Buckley to resolve his representation dilemma. We direct the reader to Mark Wallinger's video / music installation entitled "Threshold to the Kingdom" to experience this kind of feeling beyond words (http://vimeo.com/18551262). A further explanation of this narrow representational repertoire can be perhaps traced back to the lack of arts and humanities research in circle 2 that might be more inclined to use more creative forms.

A further feature of the journal article is its limited engagement with the world of practice. For example Straub and Ang (2008) note that academic journals tend to be written by researchers for researchers, and are rarely targeted at practitioners. Further, Dolnicar and Chaple (2015) used the Flesch Reading Ease Score to evaluate the readability of articles in top tourism journals. They found readability scores between 17 and 19 for the three top tourism journals indicating that they are very difficult to read.

How does circle 3 type research communicate its results? Here we find the reports, white papers and position papers for example from Problem-centred Knowledge and these are generally couched in straightforward, lay rather than academic language. We note that indigenous knowledges may be communicated in oral forms, or songs or stories or through art, crafts and artefacts. We suggest a google image search for indigenous artist Long Tom 
Tjapanangka to see the special way he paints the Australian landscape (e.g. http://www.artgallery.nsw.gov.au/collection/works/245.1998/). We note the non-fixity of web 2.0 communication technologies which are constantly being used to revise and replenish knowledge through democratic participation and open access. And finally we note the potential of new social media such as Twitter, Facebook and hashtags to bring condensed research outputs to a wider audience and with speed.

\section{Conclusion}

First and foremost the contribution of this article is a reconceptualised tourism knowledge system based on critique, synthesis, revision and extension of previous works. This system extends our understanding of epistemology, ontology, axiology, power, networks and knowledge management (Cooper, 2015). To paraphrase Law and Urry (2004) it demonstrates how tourism research is embedded in, produced by, and productive of the social. The system is more comprehensive than previous works while retaining a sense of clarity, simplicity and economy of expression. It replaces the terms Modes 1, 2 and 3 with the more meaningful descriptive terms of Disciplinary Knowledge, Problem-centred knowledge and Value-based Knowledge. However the liberal use of dotted lines underlines a fluidity in the model and the underlying messiness of the situation it seeks to describe. For example we note big seepages between the arts, humanities and social sciences, Problem-centred Knowledge and Valuesbased Knowledge. We further note that in practice the system will often work in a non-linear way especially when faced with the challenges and 'wicked problems' of a 'super-complex' world (Barnett, 2000).

Second, it finds that tourism is not just a multi-disciplinary field of enquiry but a multi-extradisciplinary one too. It identifies in circles 2 and 3 areas that were previously overlooked or under-developed and analyses their different epistemologies. The business and social science of tourism dominate our knowledge production. Overlooked areas include the disciplinary ones of sciences, humanities and arts as well as the extra-disciplinary ones of Value-based Knowledge, indigenous knowledge, Web 2.0, tacit knowledge and the zone $Y$ where the latter may combine. As a result means, theory, academic and explicit receive more attention than ends, practice, indigenous and tacit.

Third the idea of a double selectivity in tourism knowledge production is revised into a fivefold selectivity. This involves first the researcher's gaze and second the researcher's method as described by Tribe (2006). We have added third the researcher's rhetoric, fourth the audience gaze and fifth audience interpretation. In figure 1 the researcher gaze is directed from circles 2 or 3 to circle 1 . Researcher method is located in circles 2 and 3 and the researcher rhetoric describes what is created in circle 4 from the activities of circles 2 or 3. The audience gaze is represented by line e and audience interpretation occurs in circle 1 . This five-fold selectivity reveals a series of overlooked yet crucial choice points that can exert a subtle influence on the production and consumption of knowledge. 
Fourth the elements of the knowledge force field have been critiqued and rationalised so that a new set with greater explanatory capability and relevance have been developed. Person, position and ideology are retained. Rules and ends are removed through a process of rationalisation and two new forces of government and global capital are introduced. Here we re-iterate the importance of understanding the sociology of knowledge (Mannheim, 1979), knowledge-power dynamics and that the creation of knowledge is never interest-free (Habermas, 1978). We should maintain a vigilant watch on whose interests are being served and whose are overlooked through the Tourism Knowledge System and how power can form and distort the field. Fifth the system extends the process of knowledge creation set out by Tribe (2006) so that it now considers not only the widened production of tourism knowledge but its consumption too. Sixth the analysis of circle 4 demonstrates the productive power of the journal article, an underproduction of some forms of knowledge and an opportunity for novel representation techniques to better represent the richness and complexity of the researched world.

Seventh a sometimes static and possibly stale ontology of tourism is opened up, encouraged by Liburd (2013), Veijola et al. (2014) and Grimwood (2014) who stress the importance of cocreation of tourism and its knowledge so that there is a more open framing of what tourism is and can be through collaboration between the inhabitants of the world of tourism (circle 1 ) and those who research it (circles 2 and 3). Eighth it notes that research does not always complete its cycle from circle 4 back to circle 1 . This may be due to a lack of engagement with the world of practice in framing relevant research topics. Further, there is more that can be done in transmitting research outputs back into the non-academic world. Here it is also noted that tourism knowledge is over produced in its pure academic form and would benefit from translations into accessible formats, everyday language and higher readability scores. Ninth the roles and mechanisms of networks in knowledge production are analysed. Tenth it points up what is lost if tourism studies operates as a restricted field without sufficient nourishment from arts and humanities, science, web 2.0, Value-based Knowledge and indigenous knowledge. A fundamental challenge emerges from this. How can tourism knowledge become more epistemologically pluralist so that no particular mode of knowledge is overly dominant?

Finally this article helps us better understand how we make progress in tourism knowledge. The model offers an important device for ensuring greater understanding of, and reflexivity in, tourism research. We are all part of a knowledge production machine, the elements of which are often hidden or taken for granted (black boxed). If we wish to claim greater agency and participate in research for a better world we need to have a sophisticated understanding of how this machine works so that we might mobilise our forces for greater agency and more mindful research and impact in the world (of tourism). And with agency in mind we end with 
a quote from Law and Urry (2004, p. 309) which emphasises the potential role of value-based knowledge and addresses the critique alluded to earlier by Feyerabend:

"... we suggest that, if social investigation makes worlds, then it can, in some measure, think about the worlds it wants to help to make. It gets involved in 'ontological politics'."

The tourism knowledge system reveals not only the mainstream processes of theoretical advancement, practical problem-solving and real-world engagement but also the radical possibilities of ontological politics in tourism research.

\section{References}

Akena, F. A. (2012). Critical analysis of the production of Western knowledge and its implications for Indigenous knowledge and decolonization. Journal of Black Studies, 43(6), 599-619.

Amoamo, M. (2011). Tourism and hybridity: Re-visiting Bhabha's third space. Annals of Tourism Research, 38(4), 1254-1273.

Althusser, L. (1984). Essays on Ideology. London: Verso.

Althusser, L. (1969) Ideology and Ideological State Apparatuses. In School and Society, B. Cosin, ed., p. 42-280. London: Routledge and Kegan Paul.

Apple, M. (1990). Ideology and the Curriculum. London: Routledge.

Anderson, B. (2013). Affect and Emotion. In N. C. Johnson, Schein, R. H., \& Winders, J. (Ed.), The WileyBlackwell Companion to Cultural Geography (pp. 452-464). Oxford: Wiley.

Aramberri, J. (2010). Modern mass tourism (Vol. 14): Emerald Group Publishing.

Barnes, B. (2014). Interests and the Growth of Knowledge. Routledge.

Barnes, T. J. (2001). 'In the beginning was economic geography' - a science studies approach to disciplinary history. Progress in Human Geography, 25(4), 521.

Barnett, R. (1994). The Limits of Competence. Buckingham: Open University Press.

Barnett, R. (2000). Realizing the university in an age of supercomplexity. Maidenhead: McGraw-Hill International.

Barnett, R. (2004). Learning for an unknown future. Higher Education Research \& Development, 23(3), 247-260.

Bauer, I.L. (2015). Looking Over the Fence-How Travel Medicine Can Benefit From Tourism Research. Journal of Travel Medicine, 22(3), 206-207.

Bauman, Z. (2000). Liquid Modernity. Cambridge: Polity.

Becher, T. (1989) Academic Tribes and Territories, Buckingham: Open University Press.

Belhassen, Y., \& Caton, K. (2009). Advancing understandings: A linguistic approach to tourism epistemology. Annals of Tourism Research, 36(2), 335-352.

Berger, P. L., \& Luckmann, T. (1991). The social construction of reality: A treatise in the sociology of knowledge. Penguin UK.

Berry, D. M. (2008). Copy, Rip, Burn; The Politics of Copyleft and Open Source. London: Pluto Press.

Bhabba, H. (1990). The third space. In J. Rutherford (Ed.). Identity, community, culture and difference. (pp. 207-221). London: Lawrence and Wishart.

Buckley, R. (2012). Rush as a key motivation in skilled adventure tourism: Resolving the risk recreation paradox. Tourism Management, 33(4), 961-970.

Butler, R. (2015). The evolution of tourism and tourism research. Tourism Recreation Research, 40(1), 16-27. 
Butler, R., \& Hinch, T. (2007). Tourism and indigenous peoples: Issues and implications. London: Routledge.

Callon, M. (1980). Struggles and negotiations to define what is problematic and what is not: the sociologic of translation. The Social Process of Scientific Investigation, 4, 197-219.

Callon, M. (2006). What does it mean to say that economics is performative? CSI WORKING PAPERS SERIES 005. 2006.

Callon, M. (Ed.). (2001). Actor network theory. Oxford: Pergamon.

Caton, K. (2012). Taking the moral turn in tourism studies. Annals of Tourism Research, 39(4), 19061928.

Caton, K. (2014). Underdisciplinarity: Where are the humanities in tourism education? Journal of Hospitality, Leisure, Sport \& Tourism Education, 15, 24-33.

Chambers, D., \& Buzinde, C. (2015). Tourism and decolonisation: Locating research and self. Annals of Tourism Research, 51, 1-16.

Coles, T., Hall, C. M., \& Duval, D. T. (2006). Tourism and post-disciplinary enquiry. Current Issues in Tourism, 9(4-5), 293-319.

Collini, S. (2002). Defending cultural criticism. New left review(18), 73-99.

Collini, S. (2012). What are universities for? London: Penguin.

Cooper, C. (2015). Managing tourism knowledge. Tourism recreation research, 40(1), 107-119.

Crouch, D. (2000). Places around us: embodied lay geographies in leisure and tourism. Leisure studies, 19(2), 63-76.

Darbellay, F., \& Stock, M. (2012). Tourism as complex interdisciplinary research object. Annals of Tourism Research, 39(1), 441-458. doi: http://dx.doi.org/10.1016/j.annals.2011.07.002

Dei, G. J. S. (2008). Indigenous knowledge studies and the next generation: Pedagogical possibilities for anti-colonial education. Australian Journal of Indigenous Education, 37, 5-13.

Dolnicar, S., \& Chapple, A. (2015). The readability of articles in tourism journals. Annals of Tourism Research, 52, 161-166.

Echtner, C. M., \& Jamal, T. B. (1997). The Disciplinary Dilemma of Tourism Studies. Annals of Tourism Research, 24(4), 868-883.

Evans-Pritchard, D. (1989). How "They" see "Us". Native American Images of Tourists. Annals of Tourism Research, 16, 89-105.

Feyerabend, P. (1975). Against method: Outline of an anarchistic theory of knowledge. Atlantic Highlands. NJ: Humanities Press.

Filep, S. (2014). Consider Prescribing Tourism. Journal of travel medicine, 21(3), 150-152.

Foucault, M. (1971) L'ordre du Discours, Paris: Gallimard.

Foucault, M. (1974) The Archeology of Knowledge, London: Tavistock.

Foucault, M. (1980) Power / Knowledge; Selected Interviews and Other Writings 1972-77, Brighton: Harvester Press.

Gibbons, M., Limoges, C., Nowotny, H., Schwartzman, S., Scott, P., \& Trow, M. (1994). The new production of knowledge. London: Sage.

Giddens, A. (1984). The constitution of society: Introduction of the theory of structuration. Berkeley, CA: University of California Press.

Gramsci, A. (1971). Selections from the Prison Notebooks. New York: International Publishers.

Gretzel, U. (2011). Intelligent systems in tourism: A social science perspective. Annals of Tourism Research, 38(3), 757-779.

Grimwood, B. S. (2014). Advancing tourism's moral morphology: Relational metaphors for just and sustainable arctic tourism. Tourist Studies.

Gunew, S. (Ed.). (2013). Feminist Knowledge: Critique and Construct. Routledge.

Guurrbi Tours (2015). Retrieved October 15, 2015 from http://guurrbitours.com/

Habermas, J. (1978). Knowledge and Human Interests. London: Heinemann. 
Hall, C. M. (2015). Tourism and biological exchange and invasions: a missing dimension in sustainable tourism? Tourism recreation research, 40(1), 81-94.

Harrison, P., \& Anderson, B. (2012). Taking-Place: Non-Representational Theories and Geography: Non-Representational Theories and Geography. Farnham: Ashgate Publishing.

Heidegger, M. (1962). Being and Time. 1927. Trans. John Macquarrie and Edward Robinson. New York: Harper.

Hessels, L. K., \& Van Lente, H. (2008). Re-thinking new knowledge production: A literature review and a research agenda. Research policy, 37(4), 740-760.

Hollinshead, K. (2006). The shift to constructivism in social inquiry: Some pointers for tourism studies. Tourism recreation research, 31(2), 43-58.

Hollinshead, K. (2009). The "worldmaking" prodigy of tourism: The reach and power of tourism in the dynamics of change and transformation. Tourism Analysis, 14(1), 139-152.

Hughes, Michael. 2008. Ecocean, Western Australia, In Carlsen, J., Liburd, J., Edwards, D. and Forde, P. (Eds.), Innovation for sustainable tourism: International case studies. pp. 27-36. Denmark: University of Southern Denmark.

Ingold, T. (2013). Making: Anthropology, archaeology, art and architecture. Routledge.

Jafari, J., \& Brent Ritchie, J. (1981). Toward a framework for tourism education: Problems and prospects. Annals of Tourism Research, 8(1), 13-34.

Klein, J. T. (2012). Research Integration: A Comparative Knowledge Base. Thousand Oaks: Sage. DOI: http://dx.doi.org/10.4135/9781483349541.n10.

Kuhn, T. (1962). The structure of scientific revolutions. Chicago: University of Chicago Press.

Law, J., \& Urry, J. (2004). Enacting the social. Economy and society, 33(3), 390-410.

Laws, E., \& Scott, N. (2015). Tourism research: building from other disciplines. Tourism recreation research, 40(1), 48-58.

Leadbeater, C., \& Miller, P. (2004). The Pro-Am Revolution. How enthusiasts are changing our economy and society. Retrieved January 16, 2015, from http://www.demos.co.uk/files/proamrevolutionfinal.pdf?1240939425

Leiper, N. (1979). The framework of tourism: Towards a definition of tourism, tourist, and the tourist industry. Annals of Tourism Research, 6(4), 390-407.

Liburd, J. J. (2007). Sustainable Tourism, Cultural Practice and Competence Development for Hotels and Inns in Denmark. Tourism Recreation Research 32(1), 41-48.

Liburd, J. J. (2010). Sustainable tourism development In J. J. Liburd \& D. Edwards (Eds.), Understanding the sustainable development of tourism. Oxford: Goodfellow

Liburd, J. J. (2012). Tourism research 2.0. Annals of Tourism Research, 39(2), 883-907.

Liburd, J. J. (2013). Towards the Collaborative University: Lessons from Tourism Education and Research. (Professorial Dissertation), University of Southern Denmark, Denmark.

Lyotard, J. (trans. Bennington, G and Massumi, B.) (1984) The Postmodern Condition: A Report on Knowledge, Manchester: Manchester University Press.

Mannheim, K. (1979). Ideology and Utopia: An Introduction to the Sociology of Knowledge. London: Routledge and Kegan Paul.

Merleau-Ponty, M. (1962). Phenomenology of Perception London, UK: Routledge \& Kegan Paul.

Merton, R. K. (1937). The sociology of knowledge. Isis, 27(3), 493-503.

Nielsen, N., \& Wilson, E. (2012). From invisible to indigenous-driven: A critical typology of research in indigenous tourism. Journal of Hospitality and Tourism Management, 19(1), 67-75.

O'Reilly, T. (2005). Spreading the Knowledge of Innovators. What is web 2.0? Retrieved April 16, 2015, from http://oreilly.com/web2/archive/what-is-web-20.html

Picard, D., \& Di Giovine, M. A. (2014). Tourism and the power of otherness: Seductions of difference (Vol. 34): Channel View Publications.

Platenkamp, V. (2007). Contexts in tourism and leisure studies: a cross-cultural contribution to the production of knowledge. Wageningen: University of Wageningen.

Polyani, M. ([1966] 2009). The Tacit Dimension. The University of Chicago Press, London. 
Pritchard, A., Morgan, N., \& Ateljevic, I. (2011). Hopeful tourism: A new transformative perspective. Annals of Tourism Research, 38(3), 941-963.

Qiuyun, J., Guoji, F., Mulian, L., Yujun, W. \& Jingxuan, X. (2011). Research on tourism water resources carrying capacity engineering in Hainan Province. Systems Engineering Procedia 1, 384-391.

REF2014. (2011). Decisions on Assessing Research Impact. Retrieved 20/11/2014, from http://www.ref.ac.uk/media/ref/content/pub/assessmentframeworkandguidanceonsubmiss ions/GOS\%20including\%20addendum.pdf

Ren, C., Pritchard, A., \& Morgan, N. (2010). Constructing tourism research: A critical inquiry. Annals of Tourism Research, 37(4), 885-904.

Repko, A. (2008). Interdisciplinary research: Process and theory. Thousand Oaks: Sage.

Rojas, P., Malow, R., Ruffin, B., Roth, E., \& Rosenberg, R. (2011). The HIV/AIDS epidemic in the Dominican Republic: key contributing factors. Journal of the International Association of Physicians in AIDS Care (JIAPAC), 306-315.

Rydzik, A., Pritchard, A., Morgan, N., \& Sedgley, D. (2013). The potential of arts-based transformative research. Annals of Tourism Research, 40, 283-305.

Sayer, A. (1999). Long Live Postdisciplinary Studies! Sociology and the curse of disciplinary parochialism/imperialism'. Lancaster Department of Sociology, Lancaster University.

Schellhorn, M. (2010). Development for whom? Social justice and the business of ecotourism. Journal of Sustainable Tourism, 18(1), 115-135.

Shapiro, D. L., Kirkman, B. L., \& Courtney, H. G. (2007). Perceived causes and solutions of the translation problem in management research. Academy of Management Journal, 50(2), 249266.

Szostak, R. (2012). Interdisciplinary Research. Thousand Oaks, SAGE Publications.

Smith, H. A., \& Sharp, K. (2012). Indigenous climate knowledges. Wiley Interdisciplinary Reviews: Climate Change, 3(5), 467-476.

STCRC. (2010). Strategic \& Scientific Research for Australian Tourism 1997-2010. Gold Coast: Sustainable Tourism Cooperative Research Centre.

Straub, D. W., \& Ang, S. (2008). Editor's comments: readability and the relevance versus rigor debate. Management Information Systems Quarterly, 32(4), 2.

Thrift, N. (2008). Non-representational theory: Space, politics, affect. London: Routledge.

Tribe, J. (1997). The indiscipline of tourism. Annals of Tourism Research, 24(3), 638-657.

Tribe, J. (2006). The truth about tourism. Annals of Tourism Research, 33(2), 360-381.

Tribe, J. (2010). Tribes, territories and networks in the tourism academy. Annals of Tourism Research, 37(1), 7-33.

Tribe, J., Dann, G., \& Jamal, T. (2015). Paradigms in tourism research: a trialogue. Tourism Recreation Research, 40(1), 28-47.

Turkle, S. (2007). The secret power of things we hold dear. New Scientist, 194(2607), 50-52.

Veijola, S., Molz, J. G., Pyyhtinen, O., Höckert, E., \& Grit, A. (2014).Disruptive Tourism and Its Untidy Guests: Alternative Ontologies for Future Hospitalities. Palgrave Macmillan.

Walton, J. (2009). Welcome to the Journal of Tourism History. Journal of Tourism History, 1, 1 - 6.

Wilson, E. and Hollinshead, K. (2015). Qualitative tourism research: Opportunities in the emergent soft sciences. Annals of Tourism Research, 54, 30-147

Xiao, H., Jafari, J., Cloke, P., \& Tribe, J. (2012). Annals: 40-40 vision. Annals of Tourism Research, 40, 352-385.

Xin, S., Tribe, J., \& Chambers, D. (2013). Conceptual research in tourism. Annals of Tourism Research, 41, 66-88. 